\section{Indoor Gardening with Hydroponics: A Reddit Community Analysis to Identify Knowledge Gaps}

\author{
Elisa Solis-Toapanta ${ }^{1}$, Andrei Kirilenko $^{2}$, and Celina Gómez ${ }^{1}$
}

AdDitional INDEX wORDs. content analysis, data mining, online communities, social media, urban agriculture

SUMmARY. Social media platforms such as Reddit, centered on user-generated, anonymous discussions, can facilitate the exchange of information and resources across niche online communities known as "subreddits." Using data mining tools and content analysis methods, our objectives were to identify recurring questions and characterize comment ("response") accuracy from four subreddits focused on hydroponic indoor gardening ( $\mathrm{r} / \mathrm{hydro}, \mathrm{r} / \mathrm{Hydroponics,} \mathrm{r} /$ UrbanFarming, and r/Aerogarden). A total of 1617 original posts (OPs) were classified into one of ten topics and 4891 primary responses were analyzed for accuracy. The three topics with the most OPs (production systems, plant lighting, and root-zone environment), which accounted for $50 \%$ of the total OPs, were subcategorized and inductively analyzed. Most posts in the analyzed subreddits related to confusion regarding the design and implementation of appropriate hydroponic production systems. In addition, misinformation about plant lighting is a major part of discussions about growing plants indoors. There are also knowledge gaps regarding nutrient solution management, particularly about fertilizer formulation, $\mathrm{pH}$ balance, and on the impact that solution temperature has on plant growth and development. In general, there were no differences among response accuracy for all topics included in our analysis. However, regardless of topic, responses for most OPs had less than $\mathbf{5 0 \%}$ accuracy, which demonstrates that misinformation can be disseminated in social media platforms such as Reddit. As suggested by the results of this study, targeted, open access research and outreach efforts offer an opportunity to address knowledge gaps among consumers interested in indoor gardening.

$\mathrm{N}$ ew media marketing via social media provides tremendous opportunities for the green industry to engage with customers (Peterson et al., 2018; Torres et al., 2019). Likewise, agricultural outreach efforts are increasingly relying on social media platforms to reach stakeholders (Bik et al., 2015; Lubell and McRoberts, 2018; Osterrieder, 2013; Zipper, 2018). Video channels, online

Received for publication 8 Jan. 2020. Accepted for publication 25 Feb. 2020.

Published online 24 March 2020

${ }^{1}$ Environmental Horticulture Department, University of Florida, Institute of Food and Agricultural Sciences (IFAS), 1549 Fifield Hall, Gainesville, FL 326110670

${ }^{2}$ Tourism, Hospitality, and Event Management Department, University of Florida, 240B Florida Gym, Gainesville, FL 32611-0670

We thank the U.S. Department of Agriculture National Institute of Food and Agriculture, Multistate Research Project NE1835: Resource Optimization in Controlled Environment Agriculture, for supporting this research

C.G. is the corresponding author. E-mail address: cgomezv@ufl.edu.

This is an open access article distributed under the $\mathrm{CC}$ BY-NC-ND license (https://creativecommons.org/ licenses/by-nc-nd/4.0/).

https://doi.org/10.21273/HORTTECH04574-20 blogs, podcasts, and webinars are commonly being used as ubiquitous communication tools for public engagement (Davies and Hara, 2017). In addition, discussion forums like Reddit (Reddit, San Francisco, CA) have enabled bidirectional communication between scientists and the general public (Hara et al., 2019). The Reddit platform can facilitate anonymous exchange of comments, images, and other content sharing that can be used as dynamic and constantly updated learning resources (Kumar et al., 2018). Users seeking information about specific topics based on personal experiences or common interests engage in Reddit online communities known as "subreddits," which are focused discussion forums dedicated to specific themes. Nonetheless, despite active input from online community members, expert advice in social media platforms such as Reddit can be limited compared with the amount of amateurgenerated online content. This drawback is particularly visible for trending topics that have limited research-based information available to the public (Bessi et al., 2015).
As opposed to other popular social media platforms like Facebook (Facebook, Menlo Park, CA), Twitter (Twitter, San Francisco, CA), or Instagram (Facebook), Reddit's structure, centered on user-generated, anonymous discussions, make it particularly suitable for searching knowledge from like-minded participants. With a current average of 330 million monthly active users, Reddit is the sixth most visited website in the world (Statista, 2019). Over half of its users are based in the United States, making it the fourth most popular website at the national level (Alexa, 2019). In 2016, the Reddit user base for the United States was distributed as follows: $22 \%$ between the ages of 18 and 29 years; $34 \%$ between the ages of 30 and 49 years; $25 \%$ between the ages of 50 and 64 years; and $19 \%$ older than 64 years (Statista, 2016). In addition, there is an almost equal distribution between male and female users (Statista, 2019). Because Reddit has a diverse userbase who regularly ask and/or answer questions, it enables the implementation of data mining and content analysis methods to help uncover common themes within public online discussions (Chen et al., 2015; Kumar et al., 2018; Lewis et al., 2013; Wu et al., 2014). By unpacking patterns or trends used to extract common topics within subreddits, recurring questions can be identified to help describe knowledge gaps in specific online communities (Agichtein et al., 2008; Nicol, 2018).

Indoor gardening, which typically integrates small-scale edible crop (e.g., herbs, greens, and low-profile fruits and vegetables) production with indoor farming, has received limited research attention compared with commercial plant production in controlled environments. Recently ranked as one of the fastest-growing garden trends in horticulture, indoor gardening is a trending topic among online communities, which are significant drivers for this growing market segment (Garden Media Group, 2019; Thij et al., 2016). As of Nov. 2019, indoor gardening subreddits such as $\mathrm{r}$ /UrbanFarming, $\mathrm{r} /$ Hydroponics, and $\mathrm{r} /$ microgrowery, among others (each with up to 174,000 current subscribers) have numerous users who actively engage in discussions relevant to indoor gardening with hydroponic systems, which are popular among 
hobbyist gardeners (Jones, 2014; Resh, 2015). Public discussions in Reddit about personal experiences with indoor plant production are valuable resources as researchers try to address the needs of indoor gardeners. Thus, in an effort to identify knowledge gaps within online communities, the objectives of this study were to: 1) classify and quantify recurring questions (i.e., original posts or "OPs") within hydroponic indoor gardening subreddits; and 2) characterize the accuracy of comments (i.e., responses) given to OPs posted within these subreddits. We hypothesized that most questions would relate to equipment for hydroponic production and environmental requirements for indoor gardening. Furthermore, considering the lack of expert training within the subreddits evaluated, we hypothesized that a large percentage $(>50 \%)$ of responses to OPs would provide inaccurate information. To our knowledge, no other horticulture-related studies have used data mining and content analysis methods to identify knowledge gaps within active online communities.

\section{Materials and methods}

Data collection. Following procedures consistent with published approaches to Reddit content analysis (Brett et al., 2019; Chew et al., 2019; Lea et al., 2019; Sharma et al., 2017; Sowles et al., 2018), four subreddits were selected to be sampled based on relevancy to the objectives of this study, subscriber number, and community age: $r$ /hydro, $r$ /Hydroponics, $\mathrm{r}$ /Urbanfarming, and $\mathrm{r}$ /Aerogarden (Table 1). The content of those subreddits was systematically crawled (i.e., methodically browsed) using a custom code developed with Java
(Oracle Corp., Redwood Shores, CA). Data were then filtered to leave only relevant OPs and comments from each subreddit by searching for the terms "suggest," "help," "advice," "recommend," "search," "how to," "advise," and "wrong," their inflectional forms, and typical misspellings, which were previously noted as being commonly used in the selected subreddits. The dataset timeframe ranged from June 2012 to June 2019, which provided enough data points for a robust analysis from recent threads. Data were imported into Microsoft Excel (Microsoft Corp., Redmond, WA) for processing.

Topic Selection. Based on three books for hydroponic plant production (Jones, 2005, 2014; Resh, 2015) and readily available syllabi from college-level hydroponic courses at the University of Florida, Iowa State University, and The Ohio State University, a list of nine distinctive topics relevant to hydroponic indoor gardening was developed (Table 2). In addition, a tenth topic identified as "others" was included for OPs that could not be easily categorized, typically containing questions that were not included in any other topic description, or compound questions that pertained to two or more topics. Afterward, a list of specific search words for each topic was created, assuring no overlap among topic descriptions.

Data PRocessing AND CONTENT ANALYsis. All data were processed using RapidMiner Studio software (version 9.1; RapidMiner, Boston, MA) following content analysis methods described by Krippendorff (2018). The specific data preparation included seven steps: 1) tokenization (i.e., converting individual characters into aggregate sets of characters) with removal of short
$(<4)$ and long (>25) symbols; 2) removing a list of English stop words (i.e., commonly used words in the English language such as articles) obtained from Ranks NL (Amsterdam, The Netherlands); 3) removing stop words from a customized list containing words that frequently appeared within OPs but were either non-topic specific (e.g., help, advice) or unrelated to a particular topic (e.g., water, awesome, excited); 4) stemming (i.e., reducing inflected words to their word stems); 5 ) transforming words to lowercase; 6) transforming words with misspellings, variant spellings, and synonyms to a common term; and 7) filtering the most frequent and infrequent words (e.g., those encountered in over $70 \%$ and less than $1.5 \%$ of documents, accordingly). Finally, the main topics appearing in the pre-processed reviews were extracted using Latent Dirichlet Allocation methods as implemented in the RapidMiner package with optimized topic density/ word density parameters.

After completing the topic modeling, the discovered topics were manually revised for accuracy and interpretation. About $20 \%$ of all OPs were found to be misclassified because they either did not belong to a preselected subreddit or belonged to "others" and were wrongfully classified into another topic. In addition, as the topic revision was completed, commonly used jargon terms [e.g., nutes $=$ nutrients, res $=$ reservoir, and cukes $=$ cucumber $($ Cucumis sativus $)$ ] were included as topic descriptors. Finally, posts that were unrelated to hydroponic indoor gardening were removed, and the number of OPs with no responses were counted. This task was accomplished by reading all

Table 1. Subreddit description as of 19 Nov. 2019 of four online communities from which original posts and primary comments/questions related to hydroponic indoor gardening were extracted and analyzed.

\begin{tabular}{|c|c|c|c|c|}
\hline \multirow{2}{*}{$\begin{array}{l}\text { Community } \\
\text { specifics }\end{array}$} & \multicolumn{4}{|c|}{ Subreddits } \\
\hline & r/hydro & r/Hydroponics & $\mathrm{r} /$ Urbanfarming & $\mathbf{r} /$ Aerogarden \\
\hline $\begin{array}{l}\text { Description } \\
\text { message }\end{array}$ & $\begin{array}{l}\text { A home for hydroponic } \\
\text { gardeners, from } \\
\text { hobbyist to commercial } \\
\text { growers. Post grow } \\
\text { journals, questions, and } \\
\text { discussions! }\end{array}$ & $\begin{array}{l}\text { A subset of hydroculture, } \\
\text { the method of growing } \\
\text { plants without soil, using } \\
\text { mineral nutrient solutions } \\
\text { in a water solvent. }\end{array}$ & $\begin{array}{l}\text { This subreddit is for all } \\
\text { things urban farming, } \\
\text { from news and pictures to } \\
\text { advice and techniques, } \\
\text { and at any scale, from } \\
\text { a windowsill to a small } \\
\text { business. }\end{array}$ & $\begin{array}{l}\text { Welcome to Reddit's } \\
\text { AeroGarden } \\
\text { community! Feel free to } \\
\text { post things such as } \\
\text { progress pics, questions, } \\
\text { advice, sales, or coupon } \\
\text { codes, and videos. }\end{array}$ \\
\hline Age (years) & 10 & 10 & 9 & 9 \\
\hline Subscribers (no.) & 27,282 & 21,490 & 14,795 & 3,784 \\
\hline Moderators (no.) & 6 & 4 & $\mathrm{n} / \mathrm{a}$ & 1 \\
\hline
\end{tabular}


Table 2. Search words and/or concepts used to classify original posts related to hydroponic indoor gardening from the $\mathrm{r} /$ hydro, $\mathrm{r} /$ Hydroponics, $\mathrm{r} /$ UrbanFarming, and $\mathrm{r} /$ Aerogarden subreddit communities. ${ }^{\mathrm{z}}$

Cultural practices

Plant material

Root-zone environment

Plant disorders

Diseases

Pests

Environmental conditions

Plant lighting

Production system
Seeding, sowing, transplanting, shoot pruning, root pruning, pollinating, harvesting, planting, training, grafting, staking, de-topping, pinching, sucker removal, lower leaf removal, de-suckering, propagating, plant support, supporting

Cultivar, transplant, seed, cutting, vegetative, sexual, asexual, hardiness, determinate, indeterminate

Nutrient solutions, $\mathrm{pH}$, electrical conductivity, EC, fertilizer formulations, organic, solution replacement, replenish, solution temperature, water temperature, slow-release, continuous-release, aeration, water-soluble, fertilizer, plant-food, bubbles, nano-bubbles, mist, root volume, root expansion, root space, nutrient mix, nutrients, reservoir water, nutrient content, masterblend, nutes, res, flush, water chiller, $\mathrm{pH}$ up, $\mathrm{pH}$ down, acid, base, alkaline, acidic

Yellow, chlorosis, browning, necrosis, burning, deform, growing tip, stunted, slimy, brown roots, blossom-end rot, BER, fruit crack, blotchy, green shoulder, sunscald, crooking, flower abortion, fruit abortion, misshapen, protuberance, blister, indentation, catface, deficiency, toxicity, edema, oedema, intumescence, bump, lesion, salinity, excess, lack, viviparism

Bacteria, bacterial disease, bacterial canker, bacterial speck, pseudomonas (Pseudomonas syringae), bacterial spot, xanthomonas (Xanthomonas axonopodis), bacterial wilt, erwinia (Erwinia tracheiphila), ralstonia (Ralstonia solanacearum), fungus, fungal disease, aspergillus (Aspergillus niger), mold, mould, black root rot, gray mold, botrytis (Botrytis cinerea), stem canker, root rot, damping off, early blight, Pythium (Pythium sp.), fusarium (Fusarium oxysporum), fusarium wilt, white mold, sclerotinia (Sclerotinia sp.), mildew, powdery mildew, virus, viral disease, tomato leaf curl virus, slime, slimy, foam, foamy

Sanitation, prevention, integrated pest management, IPM, thrips, biological control, biocontrol, leaf miner, mite, spider mite, aphid (Aphis sp.), whitefly (Bemisia tabaci), armyworm (Pseudaletia unipuncta), bloodworm (Glycera dibranchiata), cutworm (Agrotis ipsilon), fungus gnats (Bradysia sp.), moths, lepidoptera, looper (Trichoplusia ni), mealybug, Pseudococcidae, shore fly, slug, snail

Air flow/circulation, air temp, relative humidity, carbon dioxide, $\mathrm{CO}_{2}$, enrichment, $\mathrm{HVAC}, \mathrm{CO}_{2}$ deficiency, $\mathrm{CO}_{2}$ drawdown, $\mathrm{CO}_{2}$ injector, mycelial $\mathrm{CO}_{2}$, liquid $\mathrm{CO}_{2}$, heat, cold, hot, warm, chilled

Incandescent, fluorescent, light-emitting diode, LED, lamps, intensity, quality, quantity, white light, red light, blue light, green light, CWF, SPS, broadband, narrowband, plasma, metal halide, color, lightbulb, bulb, ultraviolet, radiation, plant stretching, spacing, headroom, wattage, photosynthetic photon flux, PPF, PPDF, closeness to plants, lumen, lux, watt

Setup, design, nutrient film technique, NFT, deep water culture, DWC, Dutch bucket, ebb and flood, ebb'n'flow, drip-pass, aeroponic, aquaponic, floating, raft, drip irrigation, substrate, rockwool, rock wool cube, inorganic, peatmoss, coco coir, perlite, vermiculite, rice hull, peatlite, mixes, bark chips, sawdust, sand, pellets, fogponics, wick, kratky, kratki, liquid system, liquid hydroponic system, aggregate system, aggregate hydroponic system, pump Multi-topic questions

Others

${ }^{\mathrm{z}}$ Scientific names of organisms are included in parentheses for clarification.

OPs and identifying the topic descriptors present within each OP. Once manual classification was completed, topic classification was validated by randomly selecting $10 \%$ of OPs and reviewing all data using interrater agreement (i.e., degree of agreement among different raters for topic classification) and intrarater reliability (i.e., consistency of classification by a single rater) assessment, resulting in coefficients of 0.88 and 0.97 , respectively, which suggest that the topic descriptors used in the manual classification were highly accurate (Tinsley and Weiss, 1975). The resulting dataset included 1617 OPs and 4891 primary comments/responses to OPs. Comments for each of the 10 topics were manually rated for accuracy using the following scale: 1 = completely inaccurate; 2 = mostly inaccurate; $3=50 \%$ accurate; $4=$ mostly accurate; and $5=$ completely accurate. An expert panel consisting of a senior master student with over two years of experience with hydroponic indoor gardening, and a university professor with over 15 years of experience in controlled environment 
agriculture rated comments based on the accuracy scale. Additionally, where rating was not obvious, information provided in the comments was corroborated using various scientific resources to ensure accurate rating (e.g., Jones, 2005, 2014; Lopez and Runkle, 2017). Examples of OPs with corresponding classification, topic descriptor, response accuracy rating, and rating rationale are shown in Table 3. Lastly, to identify relevant points of discussion about the most common knowledge gaps, the top three topics based on post frequency were subcategorized and inductively analyzed (Table 4).

Data analyses. Sampled data used for the identification of each topic and subcategories for the top three topics were quantified with Microsoft Excel and graphed using SigmaPlot (version 13.0; Systat Software, San Jose, CA). A one-way analysis of variance was conducted to test the hypothesis that the mean accuracy rating differed among topics. Group means were compared using Tukey's honestly significant difference test at $P<0.05$ with statistical analysis software (JMP version 12; SAS Institute, Cary, NC).

\section{Results}

OP Classification. Questions made about the topics of production systems (19\%), plant lighting (17\%), and root-zone environment (14\%) accounted for $50 \%$ of the total OPs (Fig. 1). The other $50 \%$ of questions were distributed among all other seven topics, which included plant disorders (13\%), cultural practices $(10 \%)$, diseases $(6 \%)$, plant material (4\%), environmental conditions $(3 \%)$, pests $(2 \%)$, and “others" (12\%). Except for the topic plant lighting, all topics had at least $10 \%$ of unanswered OPs (Table 5). The subcategories and corresponding number of posts for each of the three topics with the most OPs (in parentheses) were: 1) production systems, with setup (115), general design (104), and substrate (21); 2 ) plant lighting, with lamp type (85), lamp intensity (71), and lamp setup (63); and 3 ) root-zone environment, with nutrient solution formulation (118), water temperature (47), and $\mathrm{pH}$ balance (29) (Table 4, Fig. 2).

Comment Ratings. There were no significant differences among the means of the accuracy rating in response to OPs across topics, which ranged from 2.3 to 3.5 (Table 5 ). The three topics with the highest percentage of completely accurate responses, regardless of sample size, were diseases $(40 \%)$, root-zone environment $(20 \%)$, and environmental conditions (17\%). In contrast, the topics with the lowest percentage of completely accurate responses were pests $(0 \%)$, plant disorders $(3 \%)$, and others $(4 \%)$. The three topics with the highest percentage of comments that were completely inaccurate were plant material $(43 \%)$, plant disorders $(23 \%)$, and others $(22 \%)$. The topics with the lowest percentage for completely inaccurate responses were production system $(4 \%)$, cultural practices (4\%), and plant lighting $(7 \%)$. In general, $14 \%$ to $50 \%$ of comments for OPs were rated as mostly inaccurate, $14 \%$ to $36 \%$ as $50 \%$ accurate, and $7 \%$ to $28 \%$ as mostly accurate.

\section{Discussion}

Based on our results, $50 \%$ of the most common knowledge gaps among indoor gardeners are related to production systems, plant lighting, and root-zone environment (Fig. 1). However, it is interesting to note that, regardless of the number of OPs, these three topics had the lowest percentages of unanswered questions, ranging from $5 \%$ to $14 \%$. In addition, among the responses provided to OPs, accuracy of responses provided to questions related to the topic of production system were equally distributed in the scale from 2 to 4 (i.e., mostly inaccurate to mostly accurate) (Table 5). Similarly, over 25\% of responses for questions related to plant lighting and root-zone environment were rated within 2 to 3 in the accuracy scale. This suggests that, although research-based information is available for indoor gardeners, misinformation is likely being disseminated in these subreddits.

Hobbyist gardeners struggle to discern between reliable or unreliable information available online (Jones, 2014), some of which typically lacks a scientific basis. Even if gardeners can identify reliable information, the terms and concepts used in researchbased literature tend to be considered overly technical (Schmitz, 2004). For example, unstandardized units of measurement (e.g., a mix of U.S. customary units and metric units) and varying terminology (e.g., references to essential element, nutrient, and salts) found in the scientific literature can be confusing to nonhorticulturists, such as indoor gardeners (Jones, 2014). Therefore, although there is a vast amount of scientific information available related to hydroponic use for gardening purposes, the information may not be easy to interpret by people with no formal training in plant production.

In contrast to the low percentage of unanswered questions for the top three topics, the topics pests, diseases, and "others" had $32 \%, 25 \%$, and $40 \%$ of unanswered questions, respectively (Fig. 1). As previously described, the topic "others" included complex questions that were difficult to classify based on the topic descriptors (Table 2). Respondents typically struggled with answering multiple questions within one OP, or questions that relied on visual aid for proper identification. Most responses in the topic "others" requested additional background information and/or highresolution photographs, and if OPs were not updated, questions usually remained unanswered. The ability and willingness to respond to OPs by Reddit users seems to depend on question type and on whether adequate background information is provided in the OP. Thus, clear and concise questions within OPs should help improve response rate and accuracy.

The most common questions within the topic of production system were about setups (43\%) and general design (39\%) (Fig. 2). In addition, most OPs were related to do-it-yourself (DIY) systems built and designed by indoor gardeners (data not shown). In contrast, fewer OPs asked questions about commercial countertop systems. While indoor gardeners may rely on different system setups or designs, the cost difference between a DIY system built with raw materials vs. a prefabricated commercial system can be large, with DIY systems typically being less expensive. Our data indicate that some of the most common types of systems used by do-ityourselfers (also known as "DIYers") are deep-water culture (DWC), nutrient film technique (NFT), ebband-flood, and vertical planters; aeroponic systems are used less frequently (data not shown). Correspondingly, DWC, NFT, and ebb-and-flood systems are frequently recommended for hobbyist gardeners (Jones, 2014; Resh, 2015), and closed-loop hydroponics in particular offer advantages 
Table 3. Examples of original posts and comments/responses related to hydroponic indoor gardening posted on the $r$ / hydro, $r$ /Hydroponics, $r$ /UrbanFarming, and $r$ /Aerogarden subreddit communities with a corresponding topic descriptor and classification, comment accuracy rating, and rating rationale. The accuracy rating was based on a scale where $1=$ completely inaccurate; $2=$ mostly inaccurate; $3=50 \%$ accurate; $4=$ mostly accurate; and $5=$ completely accurate.

Original post:

Topic descriptor:

Topic classification:

Comment:

Accuracy rating:

Rationale:

Original post:

Topic descriptor:

Topic classification:

Comment:

Accuracy rating:

Rationale:

Original post:

Topic descriptor:

Topic classification:

Comment:

Accuracy rating:

Rationale:

Original post:

Topic descriptor:

Topic classification:

Comment:

Accuracy rating:

Rationale:

Original post:

Topic descriptor:

Topic classification:

Comment:

Accuracy rating:

Rationale:
"Any way to estimate or test the remaining contents of spent reservoir water?"

Reservoir water; nutrient content

Root-zone environment

"Reach out to your local ag extension. The state university likely has a water lab running samples on some state-sponsored system to measure homeowners well water.

You want an esi mass spec to measure everything at once, but that will cost you a couple $\mathrm{k}$, or you can do old-fashioned chemistry and titer in a redox indicator with an eyedropper until you see a color shift. I don't remember what reagents those are, but you probably did it in chemistry laboratory in high school."

5

The comment suggests that the original poster must seek professional advice. However, it proposes chemistry measures that would be unrealistic for most indoor gardeners (italics). Regardless of feasibility, the response provided is accurate for the question.

"Help! What are these deformities/blisters on my tomato leaves? I have a DWC system, any tips on clearing them up?"

Blisters, deformities (based on pictures provided)

Plant disorders

"Probably edema, lowering humidity and decreasing watering should belp."

4

The comment provides an answer to both inquiries in the original post (OP). However, it proposes an inappropriate watering strategy considering that a deep-water culture hydroponic system is being used (italics). Therefore, although the response provided is accurate, it is not entirely correct.

"What are these? First timer here! These are my first seedlings and all of my seedlings look fine, except my basil has this mucus-looking layer on them. Not sure what they are, and not sure what to search to correct it. Any help would be great."

Identification/questions about seeds (based on pictures provided)

Plant material

"They are basil seeds, totally normal. Just overseeded, which is a good thing."

3

The comment answers the questions asked in the OP. However, it also provides inaccurate advice for sowing basil seed (italics).

"On the terrifyingly complicated topic of lighting: it seems that blue-red-purple lights are superior, yes? I almost bought a 20,000 lumen, 4-foot-long, 4-tubes LED thing for \$110 on Amazon, but after much reading, I settled for a blue-red-purple 4 -foot-long light at \$68. Was I right? Wrong? Or doesn't it matter?"

LED lamps, red, blue, lumen

Plant lighting

"Blue/red tends to be cheaper and more efficient, but I wouldn't say better. Maybe better for a beginner. There are certainly plants out there that don't like blue/red as much as white (and others that don't care at all). The bigger issue for your first few plants is to just get enough light. LEDs, CFLs, whatever, just get enough photon flux that your plants will grow. The color is 10x less important than just having enough."

2

Most of the information provided is incorrect (italics).

"Spider mites got into my indoor gardens. I've been spraying organic insecticidal soap like crazy to try and get rid of them. My gardens are right by where I work, so I can't do anything too rash. Any advice or help?"

Spider mites

Pests

"Try a pyrethrin-based pesticide, it degrades in a couple of days."

1

The comment provides inaccurate information because it suggests a pest control strategy that is not recommended for plant production under limited light and ventilation, such as that of plants found indoors. Because the half-life of pyrethrin under these conditions can extend up to $17 \mathrm{~d}$, the response is not accurate in relation to the background information provided or the question asked (National Pesticide Information Center, 2014). 
Table 4. Search words/concepts used to subcategorize original posts related to hydroponic indoor gardening from the $r$ / hydro, $r$ /Hydroponics, $r$ /UrbanFarming, and $r$ /Aerogarden subreddit communities pertaining to the three topics with the highest frequency of questions.

\begin{tabular}{|c|c|c|}
\hline Topic & Subcategory & Search words/concepts \\
\hline \multirow[t]{3}{*}{ Production system } & Setup & $\begin{array}{l}\text { Setup for existing plants, general setup, NFT, DWC, Dutch buckets, } \\
\text { ebb'n'flow, drip-pass, aeroponic, aquaponic, floating, raft, drip irrigation, } \\
\text { fogponics, deep-water culture, ebb'n'flood, wick, kratky, kratki, pump }\end{array}$ \\
\hline & General design & $\begin{array}{l}\text { Design for future plants, aggregate hydroponic system, liquid system, liquid } \\
\text { hydroponic system, aggregate system }\end{array}$ \\
\hline & Substrate & $\begin{array}{l}\text { Rockwool, rock wool cube, inorganic, peat moss, coco coir, perlite, vermiculite, } \\
\text { rice hulls, peatlite mixes, bark chips, sawdust, sand, pellets }\end{array}$ \\
\hline \multirow{2}{*}{ Plant lighting } & Lamp intensity & Intensity, quantity, wattage \\
\hline & Lamp setup & Spacing, headroom, closeness to plants \\
\hline \multirow[t]{2}{*}{ Root-zone environment } & $\begin{array}{l}\text { Nutrient solution } \\
\text { formulation }\end{array}$ & $\begin{array}{l}\text { Nutrient solutions, EC, fertilizer formulations, organic production, nutrient } \\
\text { solution replacements, slow-release, continuous-release, water-soluble, } \\
\text { fertilizer, plant-food, nutrient mix, nutrient, nutrient content, masterblend } \\
\text { fertilizer, nutes, res }\end{array}$ \\
\hline & $\mathrm{pH}$ balance & Question focused on $\mathrm{pH}, \mathrm{pH}$ up, $\mathrm{pH}$ down, acid, base, alkaline, acidic \\
\hline
\end{tabular}

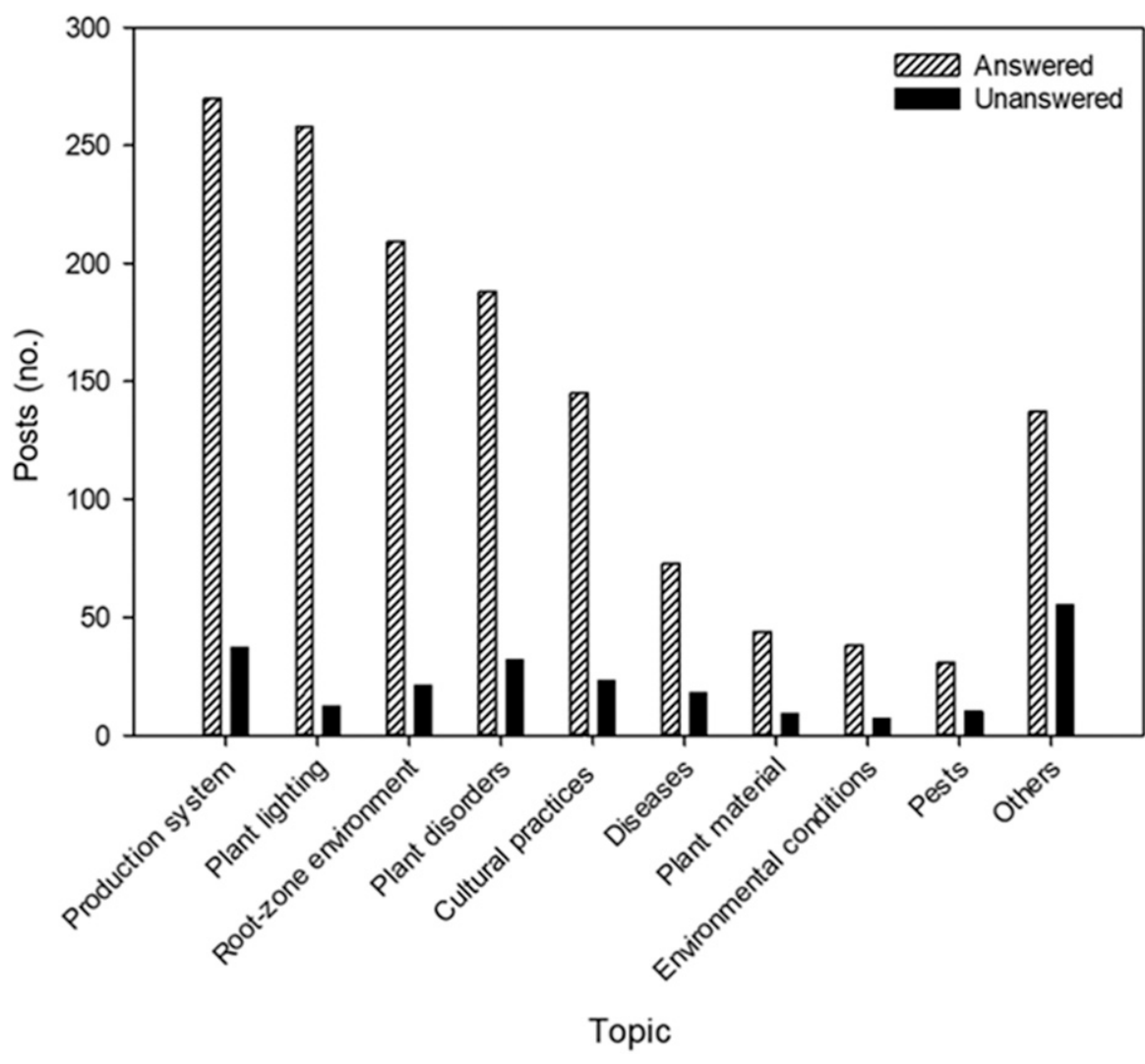

Fig. 1. Frequency of answered and unanswered questions for original posts

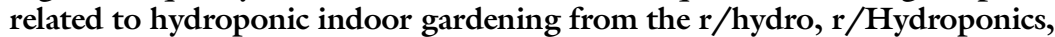
$\mathrm{r} /$ UrbanFarming, and $\mathbf{r} /$ Aerogarden subreddit communities grouped into 10 topics.

when there are space limitations, which is a general consideration among indoor gardeners (Solis-Toapanta et al., 2020). It is likely that the lack of preference for aeroponics can be attributed to the limited information available for these systems, as they have been commercially available for significantly less time than most other hydroponic systems (Gopinath et al., 2017).

Over $85 \%$ of OPs related to plant lighting were indicative of knowledge gaps related to lamp type, intensity needed for sole-source lighting, or lamp setup (Fig. 2). Although most lamp fixtures have been designed for human use, recent developments with light-emitting diode (LED) technology have enabled companies to design "horticultural-grade" lamps (Both et al., 2017). However, the widespread use of LED lamps has contributed to the significant confusion about plant responses to light quantity and quality. For example, claims about light sources that can "optimize" indoor plant production may be disseminating misleading information. That is because a general conclusion from plant lighting research with LEDs indicates that plant responses to the different light properties are highly dependent on many biological and environmental factors and thus, an "optimal" recipe for all crops and production purposes is unlikely to exist (Bugbee, 2016; Mitchell and Sheibani, 2020).

Many questions in the OPs were related to LED use, with fewer mentions of high-pressure sodium or fluorescent lamps (data not shown). In addition, one of the most recurring remarks within OPs was the search for a low-cost lamp that would provide enough light for sole-source lighting. 
Table 5. Summary statistics and characterization of response (resp.) accuracy to original posts (OPs) related to hydroponic indoor gardening from the $\mathbf{r} / \mathbf{h y d r o}, \mathbf{r}$ /Hydroponics, $r$ /UrbanFarming, and $\mathbf{r} /$ Aerogarden subreddit communities.

Response accuracy was determined based on an accuracy scale rating, where $1=$ completely inaccurate; $2=$ mostly inaccurate; $\mathbf{3}=\mathbf{5 0} \%$ accurate; $4=$ mostly accurate; and $\mathbf{5}=$ completely accurate.

\begin{tabular}{|c|c|c|c|c|c|c|c|c|}
\hline \multirow[b]{3}{*}{ Topics $^{\mathrm{z}}$} & & & racy & & & \multirow[b]{3}{*}{ Resp. (no.) } & \multirow{3}{*}{$\begin{array}{l}\text { OPs with } \\
\text { resp. (\%) }\end{array}$} & \multirow{3}{*}{$\begin{array}{c}\text { Mean } \\
\text { accuracy scale }\end{array}$} \\
\hline & 1 & 2 & 3 & 4 & 5 & & & \\
\hline & \multicolumn{5}{|c|}{ Responses (\% of total) } & & & \\
\hline Plant lighting & 7 & 37 & 35 & 7 & 14 & 281 & 95 & $2.4 \mathrm{a}$ \\
\hline Root-zone environment & 11 & 33 & 27 & 7 & 20 & 904 & 90 & $2.8 \mathrm{a}$ \\
\hline Plant disorders & 23 & 36 & 31 & 8 & 3 & 788 & 83 & $2.3 \mathrm{a}$ \\
\hline Plant material & 43 & 14 & 21 & 8 & 14 & 864 & 80 & $2.8 \mathrm{a}$ \\
\hline Environmental conditions & 17 & 33 & 17 & 16 & 17 & 501 & 82 & $3.2 \mathrm{a}$ \\
\hline Pests & 12 & 50 & 25 & 13 & 0 & 462 & 68 & $2.6 \mathrm{a}$ \\
\hline Others & 22 & 22 & 35 & 17 & 4 & 160 & 60 & $2.4 \mathrm{a}$ \\
\hline
\end{tabular}

Topics are listed in descending order based on total number of posts.

'Values within rows depict the distribution of completely inaccurate to completely accurate responses provided to the OPs for each topic.

${ }^{\mathrm{x}}$ Means within column followed by the same letter are not different based on Tukey's honestly significant difference test at $P \leq 0.05$.

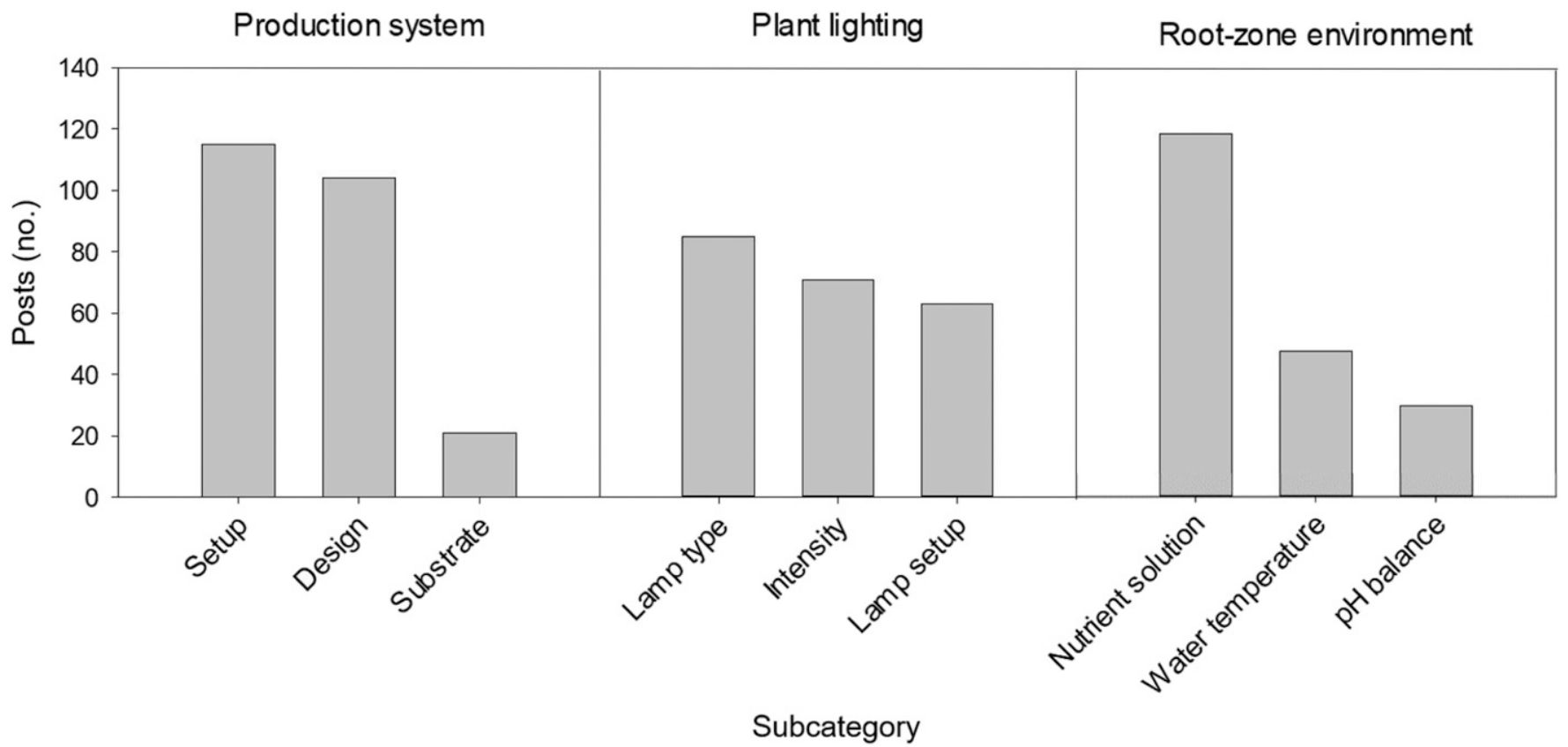

Fig. 2. Frequency of posted questions relevant to three subcategories related to hydroponic indoor gardening from the $\mathrm{r}$ /hydro, $\mathrm{r}$ /Hydroponics, $\mathrm{r}$ /UrbanFarming, and $\mathrm{r} /$ Aerogarden subreddit communities.

A large portion of the OPs suggest there is considerable confusion about the minimum amount of light required to produce both leafy greens and fruiting crops indoors. Considering that most indoor gardeners want inexpensive lamps, off-the-shelf LED lamp fixtures could be a suitable sole-source lighting option, as they have been shown to provide sufficient light to maintain pick-and-eat leafy greens within indoor environments (Paz et al., 2019; Solis-Toapanta and Gómez, 2019). However, fruiting crops require more light than leafy greens, and thus, such crops may need a different light source capable of providing the minimum light threshold for production (Dorais et al., 2017). Nonetheless, to our knowledge, no research has evaluated light requirements for indoor gardening of fruiting crops; thus, specific recommendations are still unknown.

Additionally, indoor gardeners struggle to correctly interpret and make use of appropriate light units for plant production and typically rely on photometric units such as lumens, lux, and foot-candles (Both et al., 2017; Halleck, 2018). Nonetheless, peer-reviewed and outreach materials that explain the importance of measuring light used by plants (e.g., photosynthetic photon flux, daily light integral) are readily available to the general public (Runkle, 2015, 2018). It was interesting to note that correct terms for the topic of plant lighting, such as the ones given in the previous example, were used fewer than 10 times in the entire dataset (data not shown). 
Questions in OPs about lamp setups primarily asked about the number of lamps needed to provide enough light, or about the most suitable spacing between plants and lamps. Although these questions belong to the subcategory of lamp setup, it is likely that the difficulty experienced by indoor gardeners originates from the existing misinformation about appropriate lamp types and intensities. As previously described, there is much confusion surrounding sole-source lighting, which often leads to mistakes that could result in unsuccessful indoor gardening experiences. Although there are many websites, outreach articles, and research-based information about plant lighting, the main questions identified in this study illustrate how indoor gardeners struggle to find and make use of consistent and accurate information about this topic.

Among the subcategories identified within the topic of root-zone environment, most OPs were related to nutrient solution formulation $(56 \%)$, water temperature $(23 \%)$, and $\mathrm{pH}$ balance (14\%) (Fig. 2). Nutrient solution formulation is one of the most misunderstood aspects of growing plants hydroponically by indoor gardeners, considering that most literature is limited to providing nutrient solution recipes for crops commonly grown commercially (Jones, 2014; Solis-Toapanta et al., 2020). Few hobbyist gardeners understand the complex relationship between the composition, concentration, and rate at which plants use the elements present in nutrient solutions, particularly in closed-loop hydroponic systems. For example, scientists tend to recommend adjusting the concentration of nutrients within hydroponic nutrient solutions depending on the different plant growth stages (e.g., seedling, vegetative, or reproductive) (Bugbee, 2004). Nonetheless, hydroponic plants can be grown with an array of solution formulations such as those of Hoagland and Arnon (1950), Muckle (1993), and Yuste and Gostincar (1999), among others. Although there is substantial research-based information about nutrient solution management in hydroponics (Bugbee, 2004; Christie, 2014; TrejoTéllez and Gómez-Merino, 2012), inexperienced indoor gardeners might find the task of formulating their own nutrient solution daunting, and they could benefit from premixed commercial formulations for general use. Nonetheless, it is important to consider that using commercially available nutrient solutions may not be infallible, as additional factors such as solution temperature and water $\mathrm{pH}$ may affect the success rate of hydroponic production. Considering that most indoor gardeners prefer closed-loop hydroponic systems that require constant monitoring and handling, coupled with the presumption that they struggle with understanding nutrient solution formulations, it is likely that challenges with proper solution management contribute to unsuccessful indoor gardening experiences with hydroponics.

According to Jones (2014), when growing plants hydroponically, nutrient solution temperature should be maintained similar to ambient temperature to ensure optimal plant growth (assuming temperature ranges are not limiting). However, the most frequent advice provided in response to OPs encouraged Reddit users to cool down the nutrient solution, regardless of air temperature, an action that could affect overall plant health and productivity (Jones, 2014). Finally, although most OPs within the topic of rootzone environment mentioned $\mathrm{pH}$, there seems to be a significant lack of understanding about the importance of $\mathrm{pH}$ management in hydroponic production. Most of the available literature that refers to optimal $\mathrm{pH}$ ranges originates from studies conducted to determine nutrient availability (Argo and Fisher, 2003; Jones, 2001; Dickson and Fisher, 2019). However, the effects of water quality on solution $\mathrm{pH}$, electrical conductivity, and alkalinity is an important consideration for hydroponic indoor gardeners, particularly when periodically replenishing systems with tap water. Therefore, it is important for nutrient solution formulations to be adaptable to a wide array of water qualities, as they will directly influence the gardening experience.

A possible explanation to the high frequency of OPs asking questions about indoor plant production may be related to the limited accessibility to research-based information, because scientific findings relevant to hydroponics and controlled-environment plant production have generally been published in journals with a feebased subscription. However, with the rapid changes in academic publishing and science communication, open access journals continue to become popular because they enable scientists to increase their reader base and communicate research-based findings with larger audiences (Osterrieder, 2013; Piwowar et al., 2018). According to Archambault et al. (2014), open access articles published in peer-reviewed journals will soon overcome paywalled literature. Therefore, to ensure that appropriate audiences (e.g., indoor gardeners and product suppliers) benefit from research findings relevant to indoor gardening, open access journals should be considered as the primary outlet for peer-reviewed publications in this area. In addition, close collaboration between researchers and extension professionals is critical to facilitate the delivery of outreach materials to lay audiences interested in indoor gardening.

In conclusion, the widespread use of social media can provide a quick and responsive network to gather and exchange information among science communicators and the general public. Data mining tools enabled the identification of common knowledge gaps among online communities discussing hydroponic indoor gardening. Results from this study indicate that most posts from four subreddits focused on hydroponic indoor gardening relate to confusions regarding the design and implementation of appropriate hydroponic production systems. In addition, misinformation about plant lighting seems to be a major part of discussions about growing plants indoors. There is also limited understanding about nutrient solution management, particularly about fertilizer formulation, $\mathrm{pH}$ balance, and on the impact that solution temperature has on plant growth and development. In general, there were no differences among response accuracy for all analyzed topics. However, regardless of topic, responses for most OPs had less than 50\% accuracy, which demonstrates that misinformation can be disseminated in social media. Based on the frequency and type of questions posted on Reddit about hydroponic plant production indoors, there is an opportunity to address knowledge gaps with targeted open access research 
and outreach efforts that can help foster positive experiences by indoor gardeners.

\section{Literature cited}

Agichtein, E., C. Castillo, D. Donato, A. Gionis, and G. Mishne. 2008. Finding high-quality content in social media. Proc. Intl. Conf. Web Search Data Mining, Palo Alto, CA, 11-12 Feb. 2008. ACM Press, New York, NY. p. 183-194.

Alexa. 2019. Reddit site overview. 5 Mar. 2019. <http://www.alexa.com/topsites/ countries/US>.

Archambault, É., D. Amyot, P. Deschamps, A.F. Nicol, F. Provencher, L. Rebout, and G. Roberge. 2014. Proportion of open access papers published in peer-reviewed journals at the European and world levels, 1996-2013. 18 Sept. 2019. <http:// science-metrix.com/sites/default/files/ science-metrix/publications/d_1.8_sm_ ec_dg-rtd_proportion_oa_1996-2013_ vllp.pdf>.

Argo, W.R. and P.R. Fisher. 2003. Understanding $\mathrm{pH}$ management for container-grown crops. Meister Publ., Columbus, $\mathrm{OH}$.

Bessi, A., M. Coletto, G.A. Davidescu, A. Scala, G. Caldarelli, and W. Quattrociocchi. 2015. Science vs. conspiracy: Collective narratives in the age of misinformation. PLoS One 10:e0118093.

Bik, H.M., A.D.M. Dove, M.C. Goldstein, R.R. Helm, R. MacPherson, K. Martini, A. Warneke, and C. McClain. 2015. Ten simple rules for effective online outreach. PLOS Comput. Biol. 11:1003906.

Both, A.J., B. Bugbee, C. Kubota, R.G. Lopez, C. Mitchell, E.S. Runkle, and C. Wallace. 2017. Proposed product label for electric lamps used in the plant sciences. HortTechnology 27:544-549.

Brett, E.I., E.M. Stevens, T.L. Wagener, E.L.S. Leavens, T.L. Morgan, W.D. Cotton, and E.T. Hébert. 2019. A content analysis of JUUL discussions on social media: Using Reddit to understand patterns and perceptions of JUUL use. Drug Alcohol Depend. 194:358-362.

Bugbee, B. 2004. Nutrient management in recirculating hydroponic culture. Acta Hort. 648:99-112.

Bugbee, B. 2016. Toward an optimal spectral quality for plant growth and development: The importance of radiation capture. Acta Hort. 1134:1-12.

Chen, F., P. Deng, J. Wan, D. Zhang, A.V. Vasilakos, and X. Rong. 2015. Data mining for the internet of things: Litera- ture review and challenges. Intl. J. Distrib. Sens. Netw. 11:1-14.

Chew, C., N. Rebić, C. Baldwin, N. Amiri, L. Proulx, and M.A. De Vera. 2019. 'r/Thritis', pregnancy, and parenting: A qualitative descriptive study of Reddit forums to explore information needs and concerns of women with rheumatoid arthritis. ACR Open Rheumatol. 1:485-492.

Christie, E. 2014. Water and nutrient reuse within closed hydroponic systems. Georgia Southern Univ., Statesboro.

Davies, S.R. and N. Hara. 2017. Public science in a wired world: How online media are changing science communication. Sci. Commun. 39:563-568.

Dickson, R.W. and P.R. Fisher. 2019. Quantifying the acidic and basic effects of vegetable and herb species in peat-based substrate and hydroponics. HortScience 54:1093-1100.

Dorais, M., CA. Mitchell, and C. Kubota. 2017. Lighting greenhouse fruiting vegetables, p. 159-169. In: R. Lopez and E.S. Runkle (eds.). Light management in controlled environments. Meister Media Worldwide, Willoughby, $\mathrm{OH}$.

Garden Media Group. 2019. Seeing 20/20. 19 Nov. 2019. <http://grow. gardenmediagroup.com/2020-gardentrends-report $>$.

Gopinath, P., I. Vethamoni, and $M$. Gomathi. 2017. Aeroponics soilless cultivation system for vegetable crops. Chem. Sci. Rev. Lett. 6:838-849.

Halleck, L.F. 2018. Gardening under lights: The complete guide for indoor growers. Timber Press, Portland, OR.

Hara, N., J. Abbazio, and K. Perkins. 2019. An emerging form of public engagement with science: Ask Me Anything (AMA) sessions on Reddit $\mathrm{r} /$ science. PLoS One 14:e0216789.

Hoagland, D.R. and D.I. Arnon. 1950. The water culture method for growing plants without soil. Univ. California Agr. Expt. Sta. Circ. 347.

Jones, J.B., Jr. 2001. Laboratory guide for conducting soil tests and plant analysis. CRC Press, Boca Raton, FL.

Jones, J.B., Jr. 2005. Hydroponics: A practical guide for the soilless grower. 2 nd ed. CRC Press, Boca Raton, FL.

Jones, J.B., Jr. 2014. Complete guide for growing plants hydroponically. CRC Press, Boca Raton, FL.

Krippendorff, K. 2018. Content analysis: An introduction to its methodology. Sage Publ., Thousand Oaks, CA.
Kumar, P., A. Grudz, C. Haythornthwaite, S. Gilbert, M. Esteve del Valle, and D. Paulin. 2018. Learning in the wild: Coding Reddit for learning and practice. Proc. 5lst Hawaii Intl. Conf. Syst. Sci. p. 19331942.

Lea, T., N. Amanda, and H. Jungaberle. 2019. Psychedelic microdosing: A subreddit analysis. J. Psychoactive Drugs 1-12. doi: 10.1080/02791072.2019. 1683260 .

Lewis, S.C., R. Zamith, and A. Hermida. 2013. Content analysis in an era of big data: A hybrid approach to computational and manual methods. J. Broadcast. Electron. Media 57:34-52.

Lopez, R.G. and E.S. Runkle. 2017. Light management in controlled environments. Meister Media, Willoughby, $\mathrm{OH}$.

Lubell, M. and N. McRoberts. 2018. Closing the extension gap: Information and communication technology in sustainable agriculture. Calif. Agr. 72(4): 236-242.

Mitchell, C.A. and F. Sheibani. 2020. LED advancements for plant factory artificial lighting, p. 167-184. In: T. Kozai, G. Niu, and M. Takagaki (eds.). Plant factory. 2 nd ed. Elsevier, London, UK.

Muckle, E.M. 1993. Hydroponic nutrients: Easy way to make your own. Growers Press, Princeton, BC, Canada.

National Pesticide Information Center. 2014. Pyrethrins general fact sheet. 13 June 2019. <http://npic.orst.edu/ factsheets/pyrethrins.html>.

Nicol, M. 2018. What is Reddit? A beginner's guide to the front page of the internet. 28 Oct. 2018. <https://www. digitaltrends.com/social-media/what-isReddit/>.

Osterrieder, A. 2013. The value and use of social media as communication tool in the plant sciences. Plant Methods 9:26.

Paz, M., P. Fisher, and C. Gómez. 2019. Minimum light requirements for indoor gardening of lettuce. Urban Agr. Reg. Food Systems 4:1-10.

Peterson, H., C. Boyer, L. Baker, and B. Yao. 2018. Trends in the use of newmedia marketing in U.S. ornamental horticulture industries. Horticulturae 4(32):1-14.

Piwowar, H., J. Priem, V. Larivière, J.P. Alperin, L. Matthias, B. Norlander, A. Farley, J. West, and S. Haustein. 2018. The state of OA: A large-scale analysis of the prevalence and impact of open access articles. PeerJ 6:e4375. 
Resh, H.M. 2015. Hydroponics for the home grower. CRC Press, Boca Raton, FL.

Runkle, E.S. 2015. Lighting metrics... and what matters. 20 Sept. 2019. <https:// gpnmag.com/article/lighting-metricsand-what-matters $/>$.

Runkle, E.S. 2018. An update on LED lighting efficacy. 20 Sept. 2019. <https:// www.canr.msu.edu/floriculture/uploads/ files/updateefficacy.pdf $>$.

Schmitz, J. 2004. Couple spreads hydroponics gospel in the Northwest. Fruit Growers News 43(4):40.

Sharma, R., B. Wigginton, C. Meurk, P. Ford, and C. Gartner. 2017. Motivations and limitations associated with vaping among people with mental illness: A qualitative analysis of Reddit discussions. Intl. J. Environ. Res. Public Health 14: $1-7$.

Solis-Toapanta, E. and C. Gómez. 2019. Growth and photosynthetic capacity of basil grown under constant or increasing daily light integrals for indoor gardening. HortTechnology 29:880-888.
Solis-Toapanta, E., P. Fisher, and C. Gómez. 2020. Growth rate and nutrient uptake of basil in small-scale hydroponics. HortScience 1-8, doi: 10.21273/HORTSCI 14727-19.

Sowles, S.J., M. McLeary, A. Optican, E. Cahn, M.J. Krauss, E. Fitzsimmons-Craft, D.E. Wilfley, and P.A. Cavazos-Rehg. 2018. A content analysis of an online proeating disorder community on Reddit. Body Image 24:137-144.

Statista. 2016. Distribution of Reddit users in the United States as of February 2016 , by gender. 22 July 2019 . <https:// www.statista.com/statistics/517155/ reddit-user-distribution-usa-gender $/>$.

Statista. 2019. Combined desktop and mobile visits to Reddit.com from February 2018 to July 2019 (in millions). 27 Aug. 2019. <https:// www.statista.com/statistics /443332/ reddit-monthly-visitors $/>$.

Thij, M.T., S. Bhulai, W. van den Berg, and H. Zwinkels. 2016. Twitter analytics for the horticulture industry. Data Analytics 1:75-79.

Tinsley, H.E.A. and D.J. Weiss. 1975. Interrater reliability and agreement of subjective judgments. J. Couns. Psychol. $22: 358-376$

Trejo-Téllez, L.I. and F.C. GómezMerino. 2012. Nutrient solutions for hydroponic systems, p. 1-22. In: T. Asao (ed.). Hydroponics-A standard methodology for plant biological researchers. InTech, Rijeka, Croatia.

Torres, A.P., S.S. Barton, and B.K. Behe. 2019. Evaluating the business and owner characteristics influencing the adoption of online advertising strategies in the green industry. HortTechnology 29:374-381.

Wu, X., X. Zhu, G.Q. Wu, and W. Ding. 2014. Data mining with big data. IEEE Trans. Knowl. Data Eng. 26:97-107.

Yuste, M.P. and J. Gostincar. 1999. Handbook of agriculture. Marcel Dekker, New York, NY.

Zipper, S.C. 2018. Agricultural research using social media data. Agron. J. 110:349-358. 